\title{
Complete esophageal occlusion after band ligation
}

Esophageal variceal ligation (EVL) is commonly used to treat esophageal varices given its safety profile [1]. We report an unusual complication of EVL, complete esophageal obstruction, managed with the use of a clear cap attached to the gastroscope using a "can opener" maneuver. An 84-year-old white woman with primary biliary cirrhosis intolerant to $\beta$ blockers underwent prophylactic EVL using the seven-shooter multiband ligator (Boston Scientific Inc., Natick, Massachusetts, USA) ( Fig. 1). On arriving home, she reported inability to tolerate even water. Repeat upper endoscopy demonstrated complete esophageal obstruction with a single band ( $\bullet$ Fig. 2). Multiple attempts to remove the band using the endoscope, snare, and biopsy forceps were unsuccessful. A clear-cap (D-201-11304, Olympus Inc., Tokyo, Japan) fitted gastroscope was then used to secure one side of the band and, just like the movement to remove a cap from a bottle, dislodge the band $(\bullet$ Fig. 3). The patient returned 6 days later with similar complaints. An esophagogram showed a distal esophageal obstruction ( Fig.4). Repeat endoscopy demonstrated necrotic tissue occluding the esophagus, which was managed by dilation with a through the scope balloon and insertion of a nasoenteral feeding tube. After 2 weeks the nasoenteral feeding tube was removed and the esophageal stricture dilated to $15 \mathrm{~mm}$ ( $\bullet$ Fig. 5). The patient is now eating without restrictions and has remained asymptomatic for 6 months.

Complete esophageal occlusion is a rare complication of EVL, however, removal of the occluding band may be challenging [3-5]. We report the novel use of a clear cap to successfully dislodge the band and relieve the obstruction.

Endoscopy_UCTN_Code_CPL_1AH_2AC

\section{Competing interests: None}

\section{S. W. de Melo}

University of South Alabama, Mobile, Alabama, USA

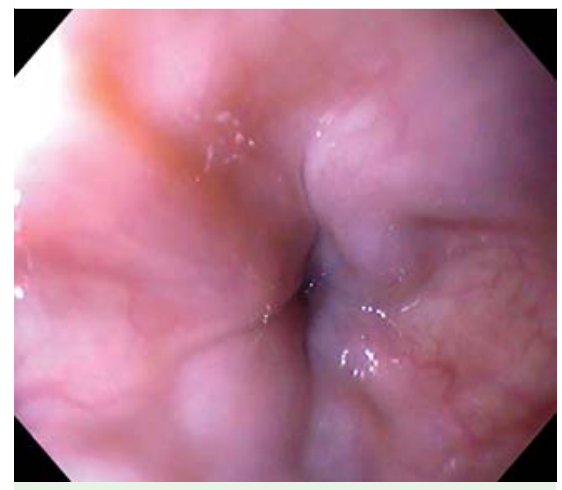

Fig. 1 Small esophageal varices seen on endoscopy.

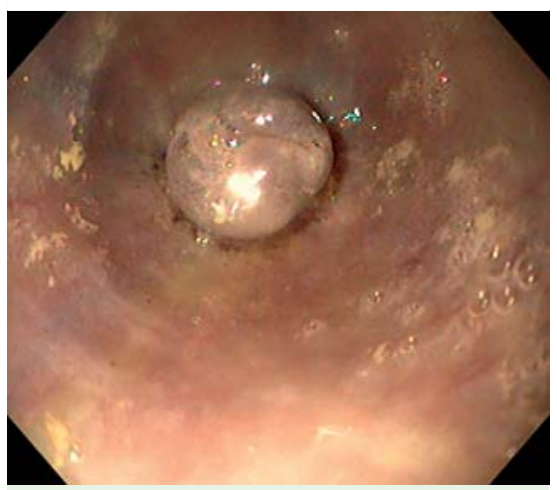

Fig. 2 Complete esophageal ligation.

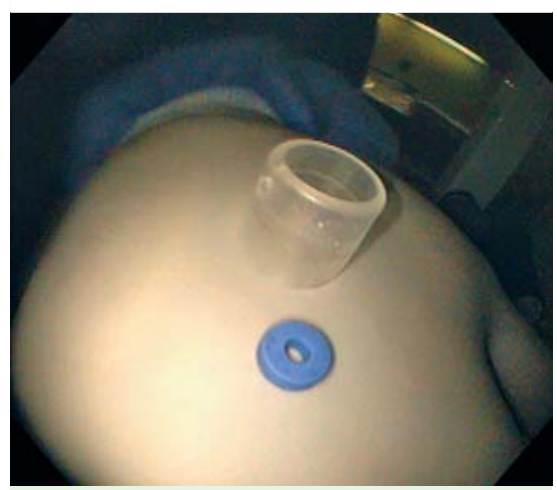

Fig. 3 Clear cap and the removed band.

\section{References}

1 Garcia-Tsao G, Sanyal AJ, Grace ND, Carey W. Prevention and management of gastroesophageal varices and variceal hemorrhage in cirrhosis. Hepatology 2007; 46: 922-938

2 Garcia-Tsao G, Bosch J. Management of varices and variceal hemorrhage in cirrhosis. $\mathrm{N}$ Engl J Med 2010; 362: 823-832

3 Nawaz A, Sarwar S, Batul A. Complete esophageal occlusion following esophageal variceal band ligation: an unusual complication; a case report. Visible Human Journal of Endoscopy 2010; 9: 1-4

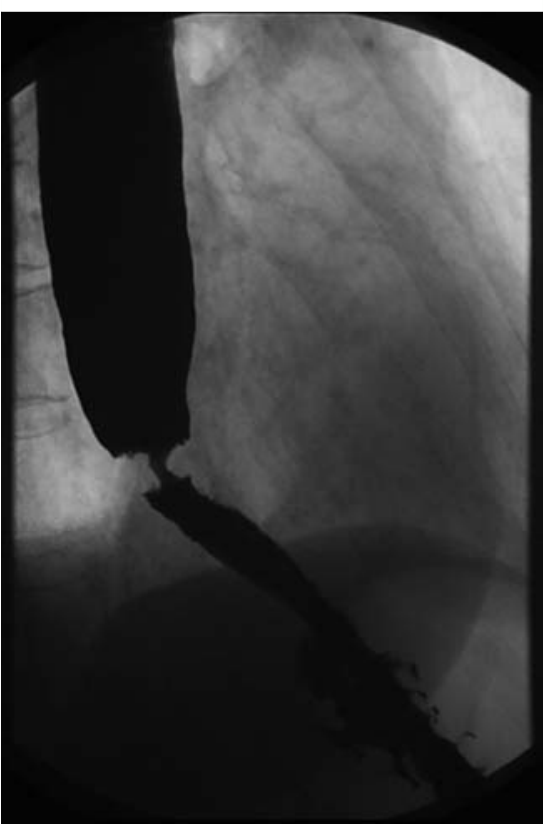

Fig. 4 Gastrografin esophagogram with distal esophageal "ring."

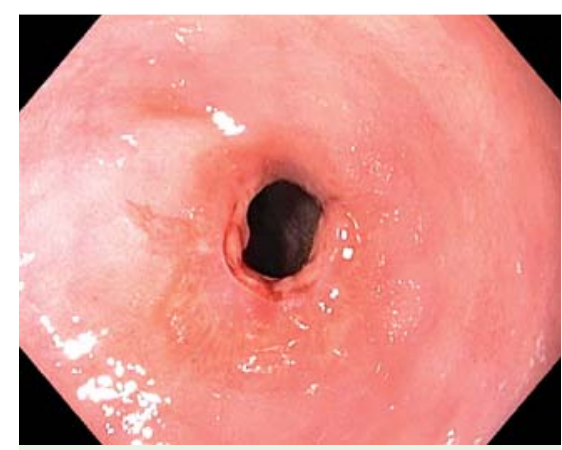

Fig. 5 Esophageal stricture after dilation.

4 Verma D, Pham C, Madan A. Complete esophageal obstruction: an ususual complication of esophageal variceal ligation. Endoscopy 2009; 41 Suppl 2: E200-201

5 Rai RR, Nijhawan S, Singh G. Post-ligation stricture: a rare complication. Endoscopy 1996; 28: 406

Bibliography

DOI $10.1055 / \mathrm{s}-0030-1256522$

Endoscopy 2011; 43: E259

(c) Georg Thieme Verlag KG Stuttgart · New York ISSN 0013-726X

\section{Corresponding author}

\section{S. W. de Melo Jr, MD}

University of South Alabama

5600 Girby Road

Mobile

AL 36693

USA

demelo@usouthal.edu 